\title{
Cranial neuropathies in uncontrolled diabetes: May not always be due to diabetic microangiopathy
}

\author{
Partha Pratim Chakraborty, Shinjan Patra, Himanshu Barman, Sugata Narayan Biswas
}

Department of Medicine, Midnapore Medical College \& Hospital, Midnapore, West Bengal, India

\section{Correspondence to} Dr Partha Pratim Chakraborty, docparthapc@yahoo.co.in

Accepted 11 May 2017

\section{DESCRIPTION}

A 22-year-old man, detected to have type 1 diabetes at the age of 9 years, presented with left-sided frontotemporal headache for 1 week followed by left-sided ptosis and binocular diplopia for 4 days. The headache was deep seated and his ocular complaints were of insidious onset and progressive in nature. On admission, he was afebrile with normal vitals except for elevated blood pressure $(160 / 110 \mathrm{~mm} \mathrm{Hg})$. He had leftsided complete ophthalmoplegia (palsies of III, IV and VI cranial nerves) along with loss of sensations along the distribution of the ophthalmic division of the left trigeminal nerve (figures 1 and 2). The pupils were equal and reacting to light and the plantar responses were down going. Anterior and posterior rhinoscopy did not reveal any bloody discharge or black eschars. Baseline biochemistry on admission revealed uncontrolled blood sugars (fasting plasma glucose: $198 \mathrm{mg} / \mathrm{dL}$; postprandial plasma glucose: $324 \mathrm{mg} / \mathrm{dL}$; haemoglobin A1c: 9.5\%) and deranged renal function (creatinine: $3.2 \mathrm{mg} / \mathrm{dL}$ ). Scraping from the nasal mucosa did not reveal fungal hyphae. MRI of the orbit elucidated an isointense lesion in T1-weighted (T1W) images in and around left orbital fissure and left cavernous sinus and also encroaching the internal carotid artery (figures 3 and 4). The MR angiography of the cerebral blood vessels was normal. The vasculitis profile including antinuclear antibody, antineutrophilic cytoplasmic antibody), serum ACE and complements study did not reveal any abnormality. With a working diagnosis of Tolosa-Hunt syndrome (THS) he was put on high-dose steroids (intravenous pulses methylprednisolone $500 \mathrm{mg}$ one time per day for 3 days followed by oral steroids $1 \mathrm{mg} / \mathrm{kg} /$ day) and

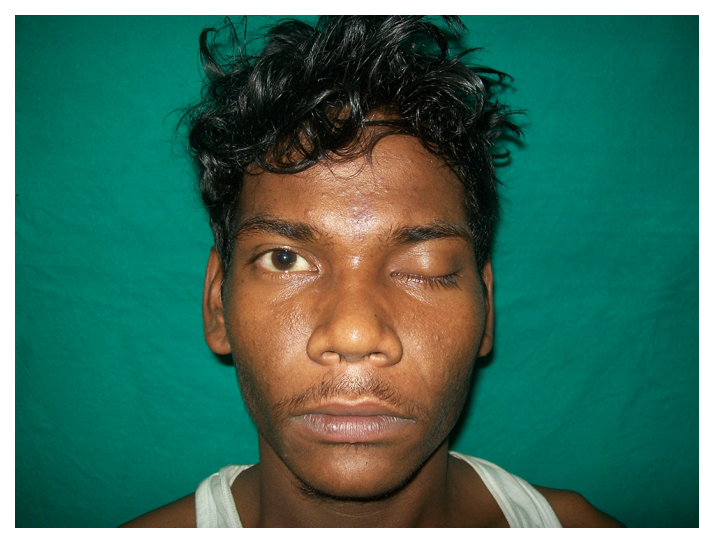

Figure 1 Left-sided ptosis.

multiple subcutaneous doses of insulin which remarkably alleviated his symptoms within 2 days. After 2 weeks, at his first follow-up visit, we noticed almost complete recovery with minimal restriction in abduction of left eye (figure 5).

Isolated cranial mononeuropathies, particularly ophthalmoplegia and facial nerve palsy, are not uncommon in patients with diabetes; however, simultaneous involvement of multiple cranial nerves due to diabetes is rare. ${ }^{1}$ The most common cause of third cranial nerve palsy in patients with diabetes is diabetic microangiopathy, in which the pupil is spared and the ocular weakness is usually painless. Slowly progressive painful ophthalmoplegia with pupillary involvement warrants ruling out expanding aneurysm of the anterior cerebral artery. The other possible causes of painful oculomotor palsy are septic cavernous sinus thrombosis, rhinocerebral mucormycosis and superior orbital fissure syndrome or the THS.

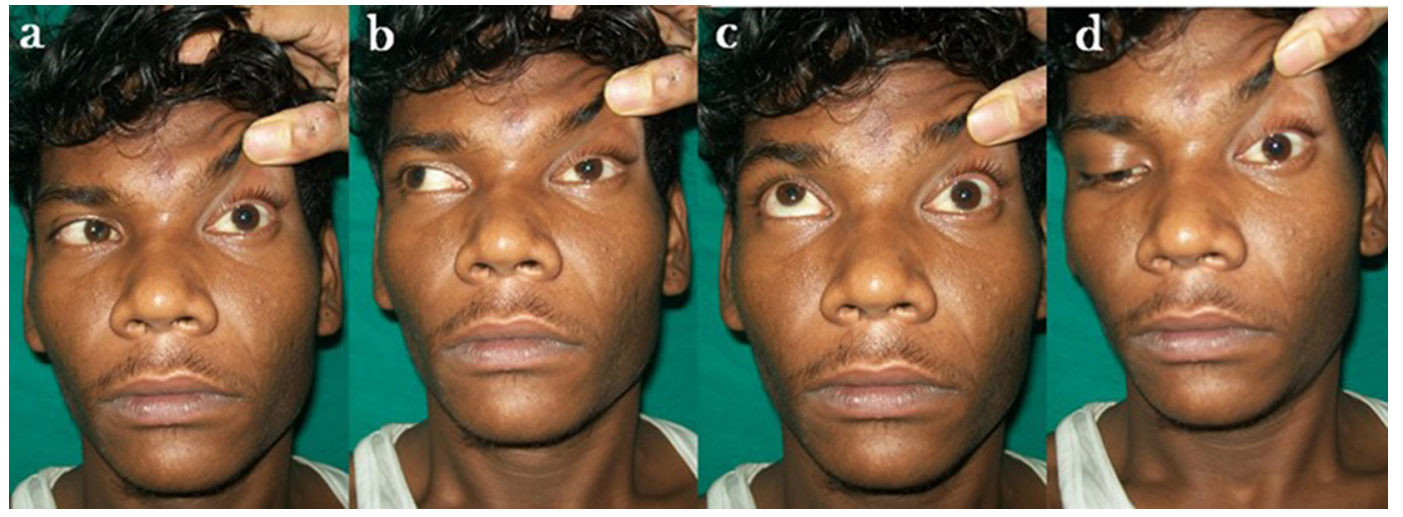

Figure 2 Complete loss of movement of left eye in left lateral gaze (A), right lateral gaze (B), upward gaze (C) and downward gaze (D). 




Figure 3 T2-weighted axial MRI showing hypointensity along the apex of left orbit (arrow).



Figure 4 T1-weighted coronal MRI showing isointense tissue in and around left cavernous sinus with narrowing of the left internal carotid artery (arrow) compared with right.
THS is a disease of unknown aetiology and is characterised by excess proliferation of fibroblasts and infiltration of septa and wall of cavernous sinus with lymphocytes and plasma cells. THS is basically a diagnosis of exclusion in any patient presenting with painful unilateral ophthalmoplegia in absence of other neurological abnormalities. The diagnostic criteria recommended by the International Headache Society takes into account clinical and radiological parameters and the combination of both these parameters have a very high sensitivity (95\%-100\%) and somewhat low specificity $(50 \%) .^{2}$ The followings are included into the criteria:

- Unilateral headache

- Headache around the ipsilateral eyebrow and eye

- Headache preceding ocular palsy by less than 2 weeks or develops with it

- Paresis of one or more of ipsilateral third, fourth and/ or sixth cranial nerves

- Granulomatous inflammation of the cavernous sinus, superior orbital fissure or orbit, demonstrated by biopsy or MRI

- No alternative diagnosis to explain the neurological abnormality

Typical THS lesions are isointense with muscle on T1W images and hypointense to isointense with fat on T2-weighted images with significant enhancement following gadolinium consistent with the pathological process of granulomatous inflammation. ${ }^{3}$ Postcontrast fat-saturated thin-slice coronal MR images through the orbital apex and cavernous sinus are most useful to pick up the abnormality.

The most striking point that effectively differentiates THS from the other possible causes of painful ophthalmoplegia is the rapid and dramatic response to systemic steroids that occurs as early as within 48 hours. THS has rarely been reported in patients with diabetes; however, in most of the studies that looked into the incidence and characteristics of cranial nerve palsy in patients with diabetes, not a single case of THS has been come across. ${ }^{14}$

To conclude, THS should be considered in all patients of unilateral painful ophthalmoplegia irrespective of the underlying comorbidities and an urgent MRI should be done to successfully treat such patient with high-dose steroids early in the course to avoid any neurological sequel.

Contributors PPC was involved in diagnosis, management, review of literature and writing the manuscript. SP also contributed in diagnosis, management, review of literature and writing the draft. HB was involved in patient management, review
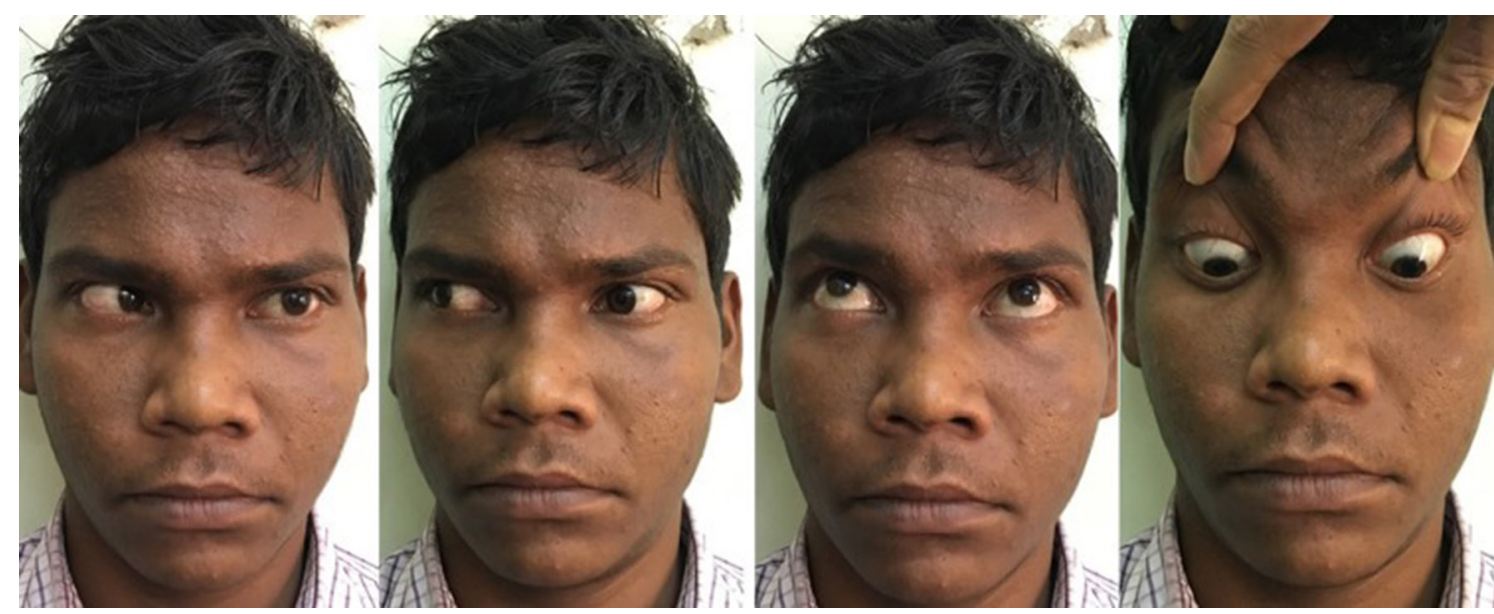

Figure 5 Minimal residual restriction of abduction in left eye after 2 weeks. 


\section{Learning points}

- Multiple cranial nerve palsy of simultaneous onset in diabetes is unlikely to be due to microangiopathy and asks for detailed evaluation.

- Painful complete ophthalmoplegia with involvement of ophthalmic division of trigeminal nerve should call for a focused imaging of the ipsilateral cavernous sinus and/or orbital apex.

- Early diagnosis of Tolosa-Hunt syndrome is of utmost importance as the therapeutic response to early systemic steroid is dramatic and complete. of literature and providing inputs during finalising the draft. SNB was involved in diagnosis, literature search and preparing the draft.

Competing interests None declared.

Patient consent Guardian consent obtained.

Provenance and peer review Not commissioned; externally peer reviewed.

(c) BMJ Publishing Group Ltd (unless otherwise stated in the text of the article) 2017. All rights reserved. No commercial use is permitted unless otherwise expressly granted.

\section{REFERENCES}

1 Greco D, Gambina F, Maggio F. Ophthalmoplegia in diabetes mellitus: a retrospective study. Acta Diabeto/ 2009;46:23-6.

2 Lance JW, Olesen J. The International classification of Headache Disorders ICHD-II. Cephalalgia 2004;24:131.

3 Yousem DM, Atlas SW, Grossman RI, et al. MR imaging of Tolosa-Hunt syndrome. AJR Am J Roentgenol 1990;154:167-70. 


\section{Images in...}

4 Watanabe $K$, Hagura R, Akanuma Y, et al. Characteristics of cranial nerve palsies in

Copyright 2017 BMJ Publishing Group. All rights reserved. For permission to reuse any of this content visit http://group.bmi.com/group/rights-licensing/permissions.

BMJ Case Report Fellows may re-use this article for personal use and teaching without any further permission.

Become a Fellow of BMJ Case Reports today and you can:

- Submit as many cases as you like

- Enjoy fast sympathetic peer review and rapid publication of accepted articles

- Access all the published articles

- Re-use any of the published material for personal use and teaching without further permission

For information on Institutional Fellowships contact consortiasales@bmjgroup.com

Visit casereports.bmj.com for more articles like this and to become a Fellow 